Check for updates

Cite this: J. Mater. Chem. B, 2019, 7, 314

Received 8th November 2018, Accepted 27th November 2018

DOI: $10.1039 / c 8 t b 02947 d$

rsc.li/materials-b

\section{Reactive oxygen species mediated theranostics using a Fenton reaction activable lipo- polymersome $\uparrow$}

\author{
Chaoqun You, (D) a Zhiguo Gao, ${ }^{\mathrm{b}}$ Hongshuai Wu, ${ }^{\mathrm{b}}$ Kai Sun, ${ }^{\mathrm{b}}$ Like Ning, ${ }^{\mathrm{a}}$ Fan Lin, \\ Baiwang Sun ${ }^{* b}$ and Fei Wang ${ }^{* a}$
}

\begin{abstract}
Recently, reactive oxygen species (ROS)-induced apoptosis has been widely studied by researchers through various means. Among them, the singlet oxygen produced by the Fenton reaction is particularly effective in killing tumor cells. Although photodynamic therapy (PDT) takes advantage of the spatialtemporal control of ROS production, the design of the Fenton reaction in an ingenious way is still a question worth exploring. Herein, we have designed and prepared a succinic peroxide-filled Fenton reaction activable $\mathrm{Pt} / \mathrm{Fe}_{3} \mathrm{O}_{4}$ @SP-PLGA lipo-polymersome that displays $\mathrm{ROS}$ mediated chemodynamic therapy (CDT). The therapeutic element, $\bullet \mathrm{OH}$, is generated under NIR irradiation/tumor acidic $\mathrm{pH}$ environment through engineering the reaction between succinic peroxide (SP) and iron oxide. Instead of using single endogenous $\mathrm{H}_{2} \mathrm{O}_{2}$ or even encapsulation, the conjugation with $\mathrm{SP}$ in the $\mathrm{Pt} / \mathrm{Fe}_{3} \mathrm{O}_{4}$ @SP-PLGA lipo-polymersome provides a more stable, high-yielding peroxygen source. The results also showed that after the addition of cisplatin, the amount of ROS production increased significantly. The proof-of-concept design of the Fenton reaction activable $\mathrm{Pt} / \mathrm{Fe}_{3} \mathrm{O}_{4}$ (ASP-PLGA lipo-polymersome with enhanced ROS-generation characteristics provides a general approach to afford potent ROS-mediated cancer therapy.
\end{abstract}

\section{Introduction}

Reactive oxygen species (ROS) at low levels in cells is an important messenger during cell proliferation or homeostasis; however, it can cause oxidative damage to cellular components and further lead to apoptosis or necrosis of cells when breaking the threshold of the ROS level. ${ }^{1,2}$ Photodynamic therapy (PDT) is one of the most widely considered strategies for ROSmediated cancer therapy, and it involves a light source, photosensitizer and oxygen. ${ }^{3}$ However, PDT has still not yet become a candidate for first-line treatment options after having been developed for decades. This is largely due to the fact that there are still unresolved challenges in traditional PDT treatment, including limited light penetration depth, the introduction of

\footnotetext{
${ }^{a}$ College of Chemical Engineering, Nanjing Forestry University, Jiangsu Key Lab for the Chemistry and Utilization of Agro-Forest Biomass, Nanjing 210037, P. R. China. E-mail: hgwf@njfu.edu.cn; Fax: +86 25 85427649; Tel: +862585427649

${ }^{b}$ School of Chemistry and Chemical Engineering, Southeast University, Nanjing 210089, P. R. China. E-mail: chmsunbw@seu.edu.cn; Fax: +86 25 52090614; Tel: +86 2552090614

${ }^{c}$ Department of Cell Biology, Nanjing Medical University, Nanjing 211166, P. R. China

$\dagger$ Electronic supplementary information (ESI) available: Synthesis procedure and other supplementary data. See DOI: 10.1039/c8tb02947d
}

divalent iron ions, oxygen reliance and other side effects of the systems. ${ }^{4}$

The emergence of nanotechnology has led to the discovery that unique nanomedicine designs can be used to effectively address these issues of PDT treatment. ${ }^{5}$ For example, the application of nanoscintillators can effectively improve the penetration depth of light, ${ }^{6}$ and the modification of trivalent iron ions to nanocarriers via coordination bonds, ${ }^{7}$ and introduce a peroxide source into a nanosystem to provide sufficient oxygen. ${ }^{8}$ Generally speaking, oxygen decreases along the electron transport chains in the mitochondria during aerobic respiration, which results in the formation of ROS throughout the lifetime of cells. ${ }^{9}$ The unbalance of endogenous ROS production and elimination leads to irreversible oxidative damage and eventually cell death. ${ }^{10}$ Therefore, it is possible to break the balance by increasing exogenous ROS to cause excessive oxidative damage, thereby achieving the purpose of killing tumor cells.

The Fenton reaction produces hydroxyl radicals (HOC) by oxidizing transition metal ions, which is a general source of ROS. This method has the advantage of avoiding insufficient penetration depth when irradiated by an external light source and has shown great promise for effective cancer therapy and bacteria killing. ${ }^{11-14}$ Moreover, some iron oxide based novel formulations were proposed for imaging and therapy. ${ }^{15,16}$ 
According to recent studies, the well-designed functionalized nanoplatforms can efficiently produce ROS for antitumor therapy with an internal microenvironment or external stimuli. ${ }^{17-19}$ In addition, cisplatin can efficiently convert $\mathrm{O}_{2}$ to $\mathrm{O}_{2}{ }^{\bullet-}$ by activating nicotinamide adenine dinucleotide phosphate oxidase (NOX), which is dismutated by the superoxide dismutase enzyme to form $\mathrm{H}_{2} \mathrm{O}_{2}$. Thus, it provides a highly oxidizing environment. ${ }^{20,21}$

Based on the acidic pH environment in cancer cells, the ideas of constructing exogenous ROS-generating agents, which trigger the Fenton reaction under NIR irradiation or a low $\mathrm{pH}$ value for cancer therapy, have gained considerable attention. ${ }^{22}$ And, instead of using single endogenous $\mathrm{H}_{2} \mathrm{O}_{2}$ or even encapsulation, the conjugation with peroxide molecules on the structure of the nanocarrier provides a more stable, high-yield peroxygen source. Herein, we have designed and prepared a succinic peroxide-filled Fenton reaction activable $\mathrm{Pt} / \mathrm{Fe}_{3} \mathrm{O}_{4} @ S P-P L G A$ lipo-polymersome (LP) that displays ROS mediated antitumor therapy. The therapeutic element, ${ }^{\bullet} \mathrm{OH}$, is generated under NIR irradiation/tumor acidic $\mathrm{pH}$ environment through engineering the reaction between succinic peroxide (SP) and iron oxide. Succinic peroxide is oxidized from succinic acid and then coupled to PEG-PLGA/PLGA polymer molecules. Iron oxide nanoparticles were employed as vehicles to carry PLGA polymers and lecithin with surface-coating groups. Hydrophilic polymers grafted with PEG units were used as capping molecules on the surface of the nanoparticles to render the resulting $\mathrm{Pt} / \mathrm{Fe}_{3} \mathrm{O}_{4} @$ @SP-PLGA LPs as water-dispersible, protonpenetrable, and biocompatible.

As the $\mathrm{Pt} / \mathrm{Fe}_{3} \mathrm{O}_{4} @$ @SP-PLGA LPs were internalized, they depolymerized to an increasingly loose structure rapidly and further collapsed while the internal temperature increased due to external NIR irradiation. Then, the released $\mathrm{Fe}^{2+}$ and dissociated SP reacted under the $\mathrm{H}^{+}$environment, thus triggering the formation of ${ }^{1} \mathrm{O}_{2}$ species. In addition, the encapsulation of cisplatin further enhanced the killing effect on tumor cells and enabled the expected synergy effect. The efficiency of $\mathrm{Pt} / \mathrm{Fe}_{3} \mathrm{O}_{4} @ S P-P L G A$ LPs for activable ${ }^{1} \mathrm{O}_{2}$ generation and cancer therapy was evaluated both in vitro and in vivo. Overall, we provide a novel strategy to achieve efficient cancer therapy by a nonphotodynamic procedure with ${ }^{1} \mathrm{O}_{2}$ generation from an engineered biochemical reaction.

\section{Results and discussion}

\subsection{Synthesis and characterization}

In the first step, the synthesis of the (PEG-PLGA) $)_{2}$-SP or PLGA-SP polymer was performed with the catalysis of $\mathrm{EDCl} / \mathrm{NHS}$. The synthesis process is shown in Fig. S1 (ESI $\dagger$ ) and the structure confirmation is shown in Fig. S2 (ESI $\dagger$ ). The chemical displacement of each proton is exactly appeared in the ${ }^{1} \mathrm{H}-\mathrm{NMR}$ data images (Fig. S2a-d, ESI $\dagger$ ) and the molecular weight results calculated by gel chromatography (GPC) further confirmed the successful production of (PEG-PLGA) $)_{2}$-SP and PLGA-SP (Table S1, ESI $\dagger$ ).

We further used UV-Vis spectroscopy to characterize the $\mathrm{Pt} / \mathrm{Fe}_{3} \mathrm{O}_{4} @ S P-P L G A$ LPs. The absorption spectra of free ICG, PEG-PLGA, (PEG-PLGA) $)_{2}$-SP, and $\mathrm{Pt} / \mathrm{Fe}_{3} \mathrm{O}_{4} @ S P-P L G A$ LPs are shown in Fig. 1a. The results showed a maximum absorption peak around $210 \mathrm{~nm}$ for PEG-PLGA and it became notable after conjugation (curve (PEG-PLGA) $)_{2}$-SP), which indicated that (PEG-PLGA $)_{2}$-SP had been successfully synthesized. In addition, a)

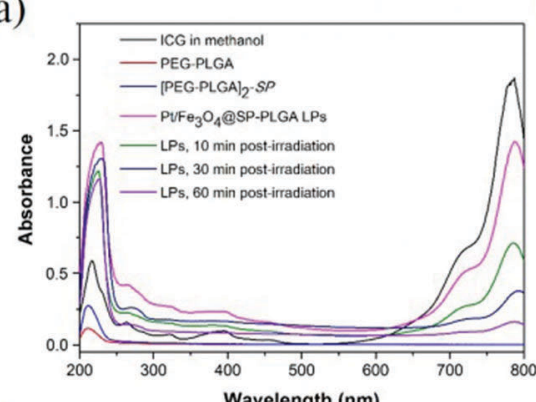

d)

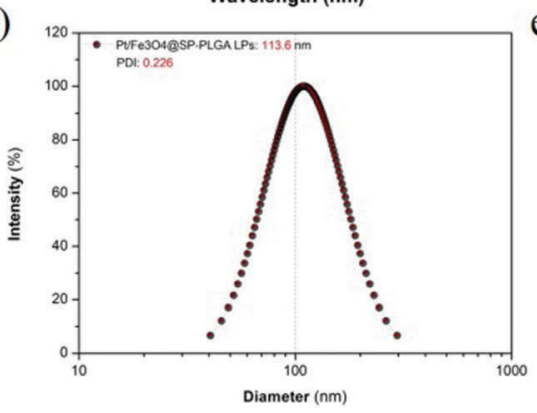

b)

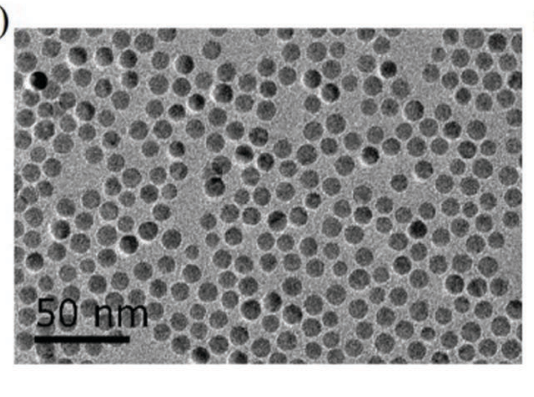

e)

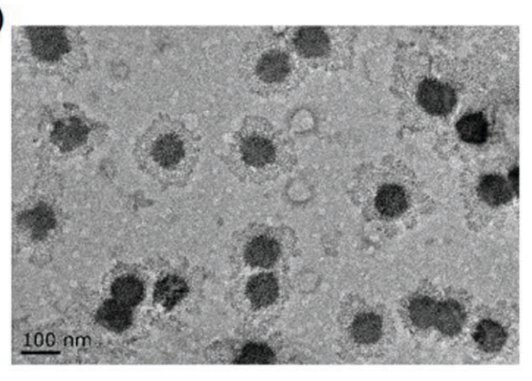

c)

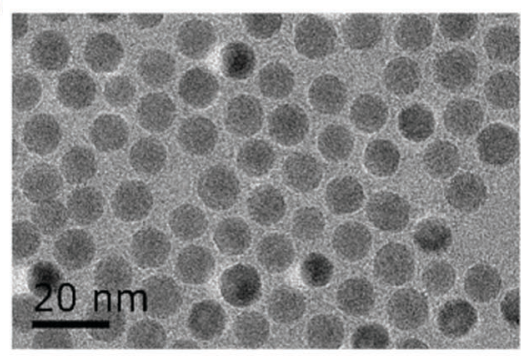

f)

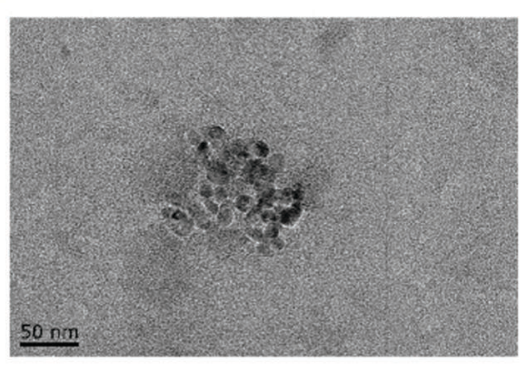

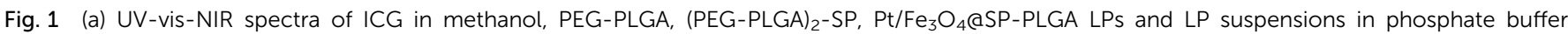

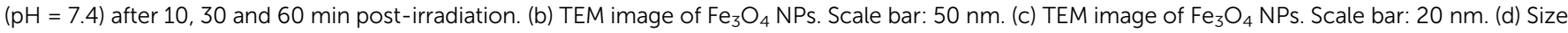

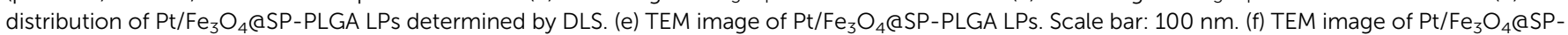
PLGA LPS. Scale bar: $50 \mathrm{~nm}$. 
compared with free ICG, the maximum absorption peak around $786 \mathrm{~nm}$ showed a slight decrease in the spectrum of the $\mathrm{Pt} / \mathrm{Fe}_{3} \mathrm{O}_{4} @$ @P-PLGA LPs, indicating that the ICG had been incorporated into the LPs. The spectra of the LP samples (containing $50 \mu \mathrm{g} \mathrm{mL} \mathrm{m}^{-1} \mathrm{ICG}$ ) after irradiation at $1.5 \mathrm{~W}$ for 10,30 , and 60 min revealed that the ICG was ablated and the encapsulated drugs had been released into solution.

\subsection{Self-assembly behavior}

Next, the Pt/ $\mathrm{Fe}_{3} \mathrm{O}_{4} @ S P-P L G A$ LPs were prepared using double emulsification, and the assembly method is shown in Scheme 1. We firstly synthesized iron oxide (IO) NPs with $\mathrm{Fe}_{3} \mathrm{O}_{4}$ to act as a metal ion source for the Fenton reaction to generate ${ }^{1} \mathrm{O}_{2}$. The Transmission Electron Microscopy (TEM) images (Fig. 1b) showed an average particle size of about $8 \mathrm{~nm}$ with harmonious polydispersity, and the image under higher resolution (Fig. 1c) further exhibited the morphological characteristics of IO NPs with a regular sphere shape.

The IO NPs were then secondarily emulsified with ICG and cisplatin-loaded PLGA polymersomes, which were grafted with SP units and mixed with lecithin, forming the $\mathrm{Pt} / \mathrm{Fe}_{3} \mathrm{O}_{4} @ S P-P L G A$ LPs. The dynamic light scattering (DLS) measurement showed good monodispersity in water with a hydrodynamic diameter of about $113.6 \mathrm{~nm}$ for the $\mathrm{Pt} / \mathrm{Fe}_{3} \mathrm{O}_{4} @ S P-P L G A$ LPs (Fig. 1d), and the TEM images clearly showed the encapsulated IO NPs (Fig. 1e and f). The change in the particle size and the encapsulated amount of $\mathrm{Fe}_{3} \mathrm{O}_{4}$, SP and Pt was investigated by adjusting the amount of (PEG-PLGA) ${ }_{2}$-SP added (Table S2, ESI $\dagger$ ). The results showed that the drug loading capacity of $\mathrm{Fe}_{3} \mathrm{O}_{4}$, SP and Pt reached 9.81\%, 3.45\% and $4.85 \%$, respectively. The obtained results showed the greatly enhanced content of endogenous $\mathrm{H}_{2} \mathrm{O}_{2}$ in the tumor cells $(100 \mu \mathrm{M}) .^{23}$ The surface zeta potential of the nanoparticles showed negative charges, which were mainly because of the conjugation of PEG groups at the shell surface (Fig. S3, ESI $\dagger$ ). Otherwise, the hydrophilic brushes at the outer surface and the lecithin layers serve as capping layers, which endow the nanocarriers with good biocompatibility and would allow for efficient water hydration.

\subsection{Drug release}

Owing to the increased anaerobic respiration under hypoxic conditions, one of the common features of various types of tumors, especially solid tumors, is that tumors are acidic internally. ${ }^{24}$ Therefore, the investigation of encapsulated cisplatin or iron release from $\mathrm{Pt} / \mathrm{Fe}_{3} \mathrm{O}_{4}$ @SP-PLGA LPs under different $\mathrm{pH}$ conditions to mimic the intratumoral environment was carried out. ${ }^{25}$

As shown in Fig. 2a, the amounts of released cisplatin obviously increased upon exposure to NIR laser $(87.78 \%)$ as compared with the control group (9.55\%) at $\mathrm{pH}=7.4$ for $36 \mathrm{~h}$. Specifically, about $80.38 \%$ cisplatin was released in the control group and about $98.86 \%$ cisplatin was released upon exposure to the NIR laser at $\mathrm{pH}=5.5$ in $30 \mathrm{~h}$. Furthermore, the released amount of cisplatin upon NIR irradiation significantly increased to about $99.98 \%$ in $36 \mathrm{~h}$, which was slightly higher as compared with that without NIR irradiation. The TEM images in Fig. 2b show that the polymeric shell of the LPs was fully depolymerized under NIR irradiation.

In the release investigation of $\mathrm{Fe}_{3} \mathrm{O}_{4}$, the results showed that $16.27 \%$ Fe was dissolved from the LPs within the initial $6 \mathrm{~h}$ and it reached $22.47 \%$ at $\mathrm{pH}=5.5$ after $12 \mathrm{~h}$ (Fig. 2c). However, it only reached $0.06 \%$ in $12 \mathrm{~h}$ incubation at $\mathrm{pH}=7.4$ without NIR irradiation. Moreover, the highest amounts of released Fe reached $89.68 \%$ upon NIR irradiation at $\mathrm{pH}=5.5$ for $36 \mathrm{~h}$. Moreover, the released Fe from the depolymerized LPs is clearly visible in Fig. 2d.

More importantly, the shell of the lecithin layers was depolymerized to a loose structure rapidly due to the intracellular acidic conditions and it was further aggravated upon NIR irradiation, which facilitated the penetration of $\mathrm{H}^{+}$and dissolution of iron(II)
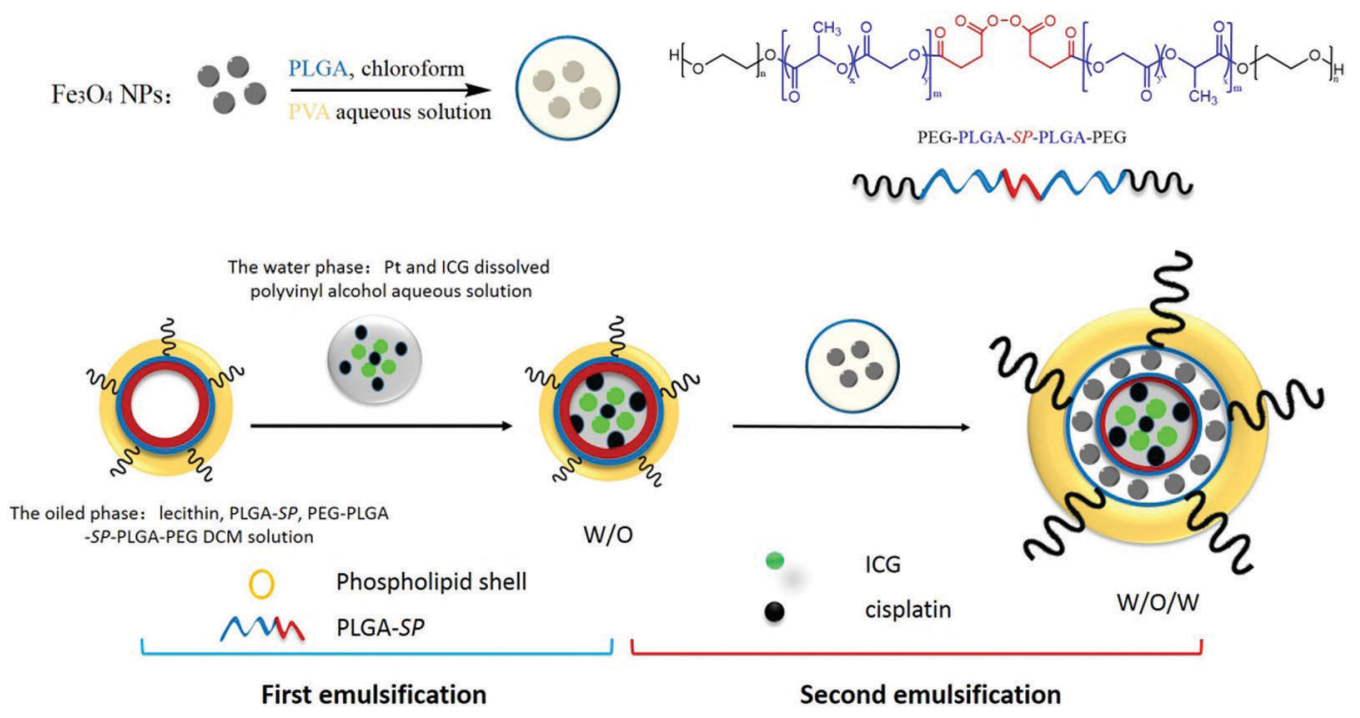

Scheme 1 Cisplatin and ICG-encapsulated $\mathrm{Fe}_{3} \mathrm{O}_{4}$-embedded SP-PLGA lipo-polymersomes (Pt/Fe $3 \mathrm{O}_{4} @$ QSP-PLGA LPS) were prepared via a doubleemulsion process. 
a)

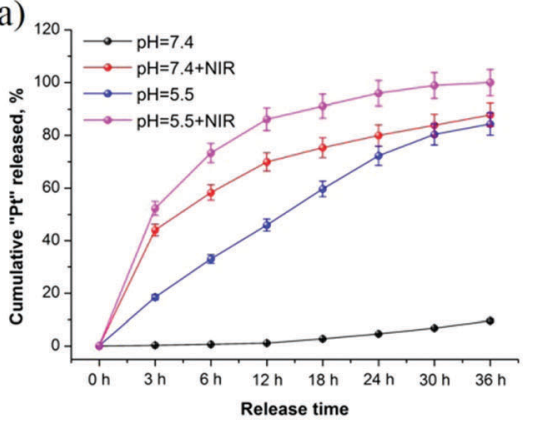

c)

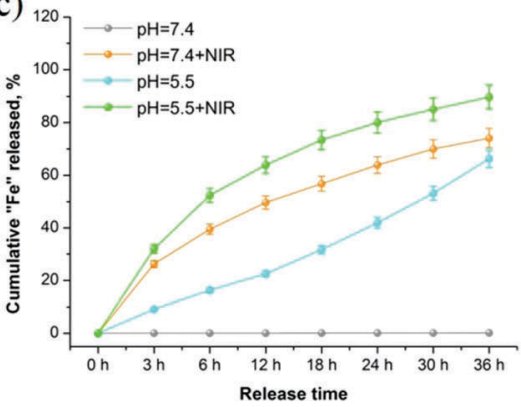

b)

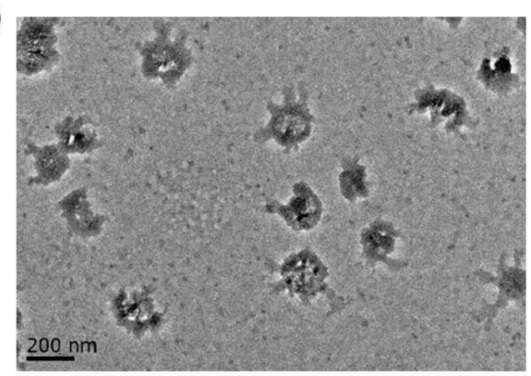

d)

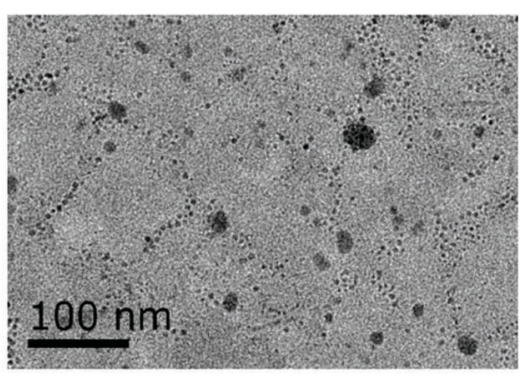

Fig. 2 (a) NIR dependent release of cisplatin (Pt) from the Pt/Fe $\mathrm{O}_{4}$ @SP-PLGA LPs at different pH values (7.4 and 5.5). (b) TEM image of Pt/Fe $3 \mathrm{O}_{4}$ (aSPPLGA LPs in PBS ( $\mathrm{pH}=7.4$ ) after $3 \mathrm{~h}$ post-irradiation. (c) NIR dependent release of $\mathrm{Fe}_{3} \mathrm{O}_{4}$ (Fe) from the Pt/Fe $3 \mathrm{O}_{4} @ \mathrm{QSP}-\mathrm{PLGA} L \mathrm{LS}$ at different $\mathrm{pH}$ values (7.4, 5.5). (d) TEM image of $\mathrm{Pt} / \mathrm{Fe}_{3} \mathrm{O}_{4}$ (aSP-PLGA LPs in PBS ( $\mathrm{pH}=7.4$ ) after $36 \mathrm{~h}$ post-irradiation.

ions and cisplatin from the inside of the $\mathrm{Pt} / \mathrm{Fe}_{3} \mathrm{O}_{4} @ S$ SP-PLGA LPs in the acidic environment.

\subsection{Intracellular uptake}

We further studied the cellular uptake efficiency of the $\mathrm{Pt} / \mathrm{Fe}_{3} \mathrm{O}_{4} @ S P-P L G A$ LPs with MCF-7 cells for different incubation periods. As shown in Fig. 3a, no significant fluorescence intensity could be observed in the cells in the initial $1 \mathrm{~h}$. However, the cells treated with LPs exhibited strong fluorescence intensity after having been incubated for $3 \mathrm{~h}$. The results of flow quantification showed that the fluorescence intensity increased obviously, and a 6.3-fold higher fluorescence intensity was detected in the MCF-7 cells incubated for $12 \mathrm{~h}$ compared to that observed in $3 \mathrm{~h}$ (Fig. $3 \mathrm{~b}$ and c). The results indicated that the cellular uptake of $\mathrm{Pt} / \mathrm{Fe}_{3} \mathrm{O}_{4} @$ @SP-PLGA LPs was increased along with incubation time and the fluorescence signals mainly gathered around the cellular nuclei, indicating that the $\mathrm{Pt} / \mathrm{Fe}_{3} \mathrm{O}_{4} @ S P-P L G A$ LPs were entrapped inside the lysosome vesicles. We further used a mitochondrial dye, Mito-Tracker Green (MTG), to label the mitochondria for imaging observation (Fig. 3d). The cellular uptake of the present LPs can be blocked by pretreating the MCF-7 cells with PEG-lecithin shell, ${ }^{26}$ which confirmed that the internalization of the $\mathrm{Pt} / \mathrm{Fe}_{3} \mathrm{O}_{4} @ S P-P L G A$ LPs was accelerated by the specific compatibility between phospholipids and the cell membrane.

\subsection{ROS generation in cells}

Due to the high reactivity of ${ }^{1} \mathrm{O}_{2}$ species in a very short period of half-life within tens of nanoseconds, the diffusion distance of ${ }^{1} \mathrm{O}_{2}$ in the cytoplasm is limited. ${ }^{27}$ However, the high oxidative properties of ${ }^{1} \mathrm{O}_{2}$ species may lead to the immediate oxidation of substances in the cytoplasm, which in turn will lead to an increase in intracellular ROS levels. In this respect, we used a $2^{\prime}, 7^{\prime}$-dichlorodihydrofluorescein diacetate probe (DCFH-DA) to study the changes of ROS levels in $\mathrm{Pt} / \mathrm{Fe}_{3} \mathrm{O}_{4} @ S P$-PLGA LP-treated cells.

Before the evaluation in vitro, we investigated the - $\mathrm{OH}$-generating activity of Fenton-like $\mathrm{Fe}^{2+}$ at a $\mathrm{pH}$ of 5.5 and the scavenging effect of GSH on ${ }^{\circ} \mathrm{OH}$. Methylene blue (MB), a dye that can be degraded by ${ }^{\circ} \mathrm{OH}$, was selected as an indicator of $\bullet \mathrm{OH}$ generation. The results showed that a significant decrease in absorbance was observed when MB was incubated with LPs for $30 \mathrm{~min}$ in the buffer, whereas no apparent change in the MB absorbance was detected after the same treatment in aqueous solution (Fig. S4, ESI $\dagger$ ). These results suggested the $\mathrm{Fe}^{2+}$-driven Fenton-like reaction can effectively produce ${ }^{\bullet} \mathrm{OH}$ using the prepared LPs.

Next, the ${ }^{\bullet} \mathrm{OH}$ generation in vitro was investigated. As shown in Fig. S5a (ESI $\dagger$ ), ${ }^{\bullet} \mathrm{OH}$ was generated rapidly and the amount of - $\mathrm{OH}$ increased with incubation time. Furthermore, the results showed significantly increased ROS levels in the cells when incubated for more than $3 \mathrm{~h}$ (Fig. S5b and c, ESI $\dagger$ ). Based on the release investigation, the results indicated that the ROS generated

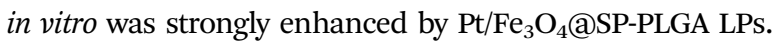

Supposing that each SP contains a peroxy bond producing one ${ }^{1} \mathrm{O}_{2}$ molecule without bleaching, the intracellular ROS levels that we estimated were $0.2,6.9$, and $18.0 \times 10^{5}$ for MCF-7 cells incubated with 10,20 , and $30 \mathrm{mg} \mathrm{mL}{ }^{-1} \mathrm{Fe}_{3} \mathrm{O}_{4}$ in $\mathrm{Pt} / \mathrm{Fe}_{3} \mathrm{O}_{4} @ S P-P L G A$ LPs, respectively (Fig. 4a). The results demonstrated the rapid increase of ${ }^{\circ} \mathrm{OH}$ generation once a 
a)

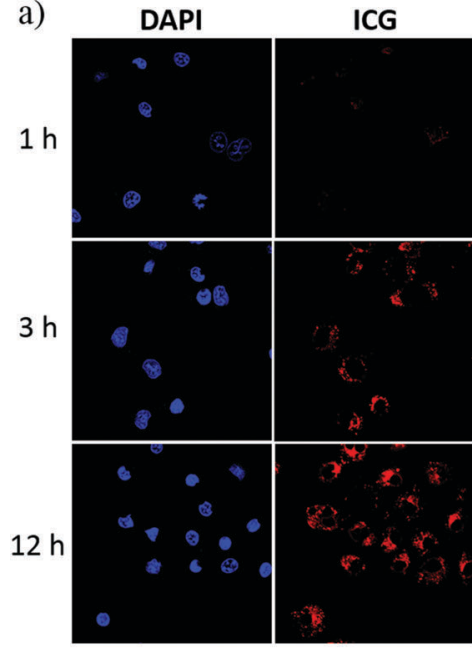

d)

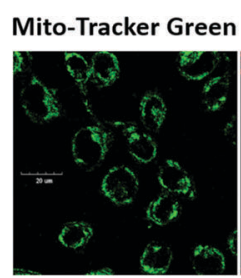

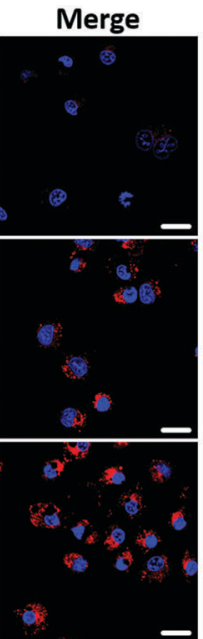

b)

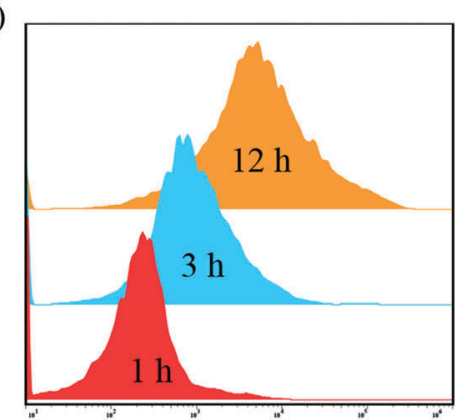

c)

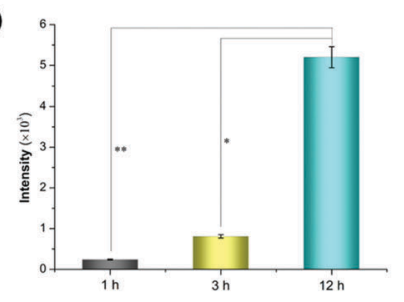

Merge

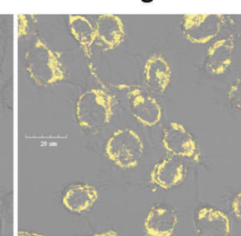

Fig. 3 (a) CLSM images of MCF-7 cells incubated with Pt/Fe $3 \mathrm{O}_{4}$ @SP-PLGA LPs for different periods of time at an equivalent ICG concentration of $45 \mu \mathrm{g} \mathrm{mL}^{-1}$ (scale bar, $20 \mu \mathrm{m}$ ). Flow cytometric analysis (b) and quantitation (c) of the ICG fluorescence intensity in MCF-7 cells. (d) Internalization of the ICG-labeled Pt/Fe ${ }_{3} \mathrm{O}_{4}$ @SP-PLGA LPs (equivalent to $45 \mu \mathrm{g} \mathrm{mL}{ }^{-1}$ ICG) by MCF-7 cells for $6 \mathrm{~h}$, analyzed by CLSM (Scale bar, $20 \mu \mathrm{m}$ ).

certain concentration is reached (Fig. $4 \mathrm{~b}$ and c). The obtained results were comparable to the reported threshold for spherical tumors for ${ }^{1} \mathrm{O}_{2}$ species. ${ }^{28}$ Furthermore, compared with those incubated with PBS, $\mathrm{Fe}_{3} \mathrm{O}_{4} @ P L G A, \mathrm{Fe}_{3} \mathrm{O}_{4} @ S P-P L G A$, and $\mathrm{Pt} / \mathrm{Fe}_{3} \mathrm{O}_{4} @$ @P-PLGA LPs, the results showed increased ROS levels with a significantly high median fluorescence intensity (MFI) for the cells incubated with $\mathrm{Pt} / \mathrm{Fe}_{3} \mathrm{O}_{4}$ @SP-PLGA LPs with NIR irradiation (Fig. $4 \mathrm{~d}$ and e). The results further indicated that ${ }^{\bullet} \mathrm{OH}$ was generated by the Fenton reaction and enhanced by released SP and Pt.

\subsection{Cytotoxicity study}

The cytotoxicity of these nano-formulations was further studied by using standard MTT assay. As shown in Fig. 5a, $\mathrm{Fe}_{3} \mathrm{O}_{4} @$ @PPLGA (without Pt or NIR irradiation) showed unobvious cytotoxicity to MCF-7 cells at low concentration and the cell viability decreased rapidly to $52.18 \%$ when the concentration of $\mathrm{Fe}_{3} \mathrm{O}_{4}$ increased to $20 \mu \mathrm{g} \mathrm{mL}^{-1}$. Furthermore, the cell viability further showed a certain degree of reduction with the encapsulation of cisplatin in $\mathrm{Pt} / \mathrm{Fe}_{3} \mathrm{O}_{4} @$ @SP-PLGA LPs (37.28\%). However, the MCF-7 cells treated with $\mathrm{Pt} / \mathrm{Fe}_{3} \mathrm{O}_{4} @$ @PP-PLGA LPs with NIR irradiation exhibited much lower cell viability $(1.42 \%)$ than the control group, $\mathrm{Fe}_{3} \mathrm{O}_{4} @ S P-P L G A$ or Pt $/ \mathrm{Fe}_{3} \mathrm{O}_{4} @ S P-P L G A$ LPs after incubation for $24 \mathrm{~h}$.

According to the obtained results, we further studied the effect of the dose amount of SP or Pt on cell viability. As presented in Fig. 5b, the effect of SP content on cell viability is notable and the cell viability between the LP group and the control group showed a significant difference $\left({ }^{*} P<0.05\right)$ at a concentration of $2.0 \mu \mathrm{g} \mathrm{mL}{ }^{-1}$. In addition, for the enhanced effect of cisplatin, the cell viability between the LP group and the control group showed a significant difference $\left({ }^{* *} P<0.01\right)$ at a concentration of $8.0 \mu \mathrm{g} \mathrm{mL}^{-1}$ (Fig. 5c). The obtained results indicated that the addition of SP or Pt in the LPs can enhance the therapeutic effect to a certain extent and the results were consistent with that of ROS generation. We further evaluated the induced apoptosis of $\mathrm{Pt} / \mathrm{Fe}_{3} \mathrm{O}_{4} @ S P-P L G A$ LPs on tumor cells. As shown in Fig. 5d, the apoptosis induced by LPs with NIR irradiation was obviously higher than that for treatment with LPs alone. The results suggest that the present LPs show good inhibition on MCF-7 cells.

More importantly, the addition of the LPs may produce a certain amount of $\mathrm{H}_{2} \mathrm{O}_{2}$ and further promote the formation of hydroxyl radicals, subsequently leading to cell apoptosis, which shows sensitivity to cisplatin. This study provides a new route for reactive oxygen species mediated combined antitumor therapy.

\subsection{In vivo imaging study}

To further observe the delivery of drug loaded nanocarriers in vivo, the distribution of $\mathrm{Fe}_{3} \mathrm{O}_{4} @$ @SP-PLGA LPs at the tumor tissues was studied. As shown in Fig. 6a, in the initial stage of injection ( $6 \mathrm{~h}$ post-injection), the nanocarriers were mainly accumulated in the tumor site and some of the nanocarriers 


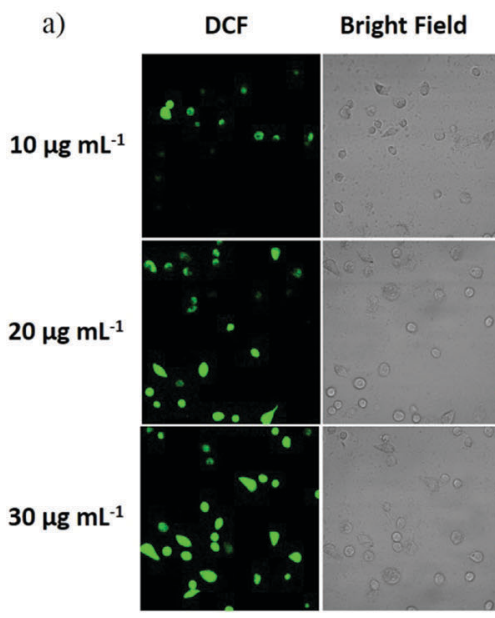

d)

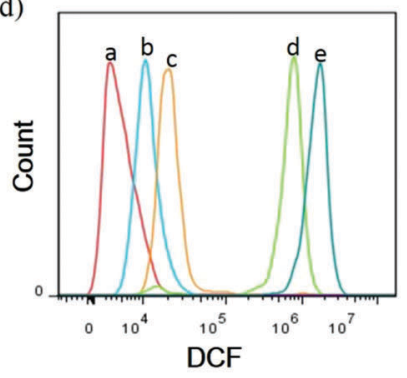

Merge

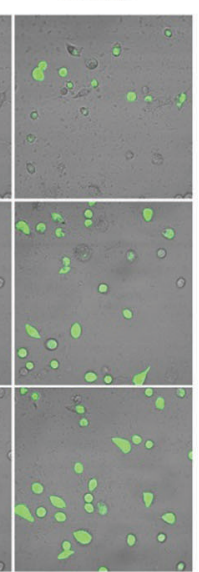

b)

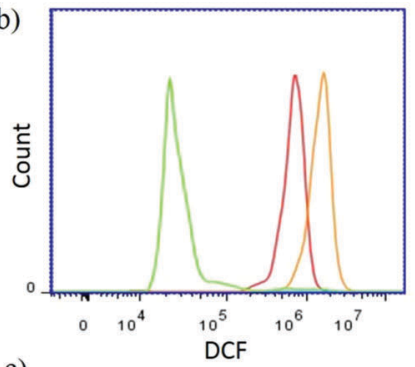

c)

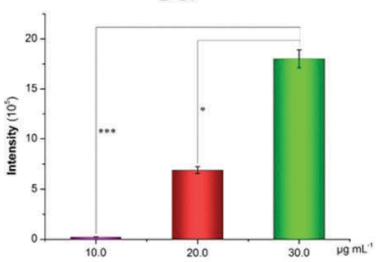

e)

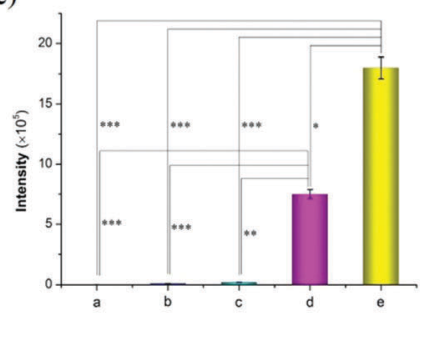

Fig. 4 Evaluation of the capability of ROS generation of Pt/Fe $3 \mathrm{O}_{4}$ @SP-PLGA LPs in vitro. (a) CLSM images of MCF-7 cells incubated with Pt/Fe $3 \mathrm{O}_{4} \mathrm{a}$ SP-PLGA LPs at different LP concentrations. Flow cytometric analysis (b) and quantitation (c) of ROS levels in MCF-7 cells. (d) CLSM images of MCF-7 cells

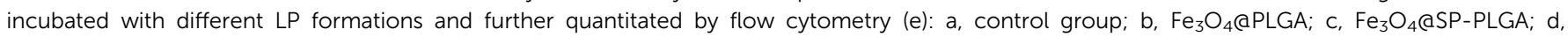
$\mathrm{Pt} / \mathrm{Fe}_{3} \mathrm{O}_{4} \mathrm{QSP}-\mathrm{PLGA} ;$ and e, Pt/Fe $\mathrm{O}_{4} \mathrm{QSP}-\mathrm{PLGA}+\mathrm{NIR} .(n=3) .{ }^{*}: P<0.05, * *: P<0.01$ and ***: $P<0.001$.

a)

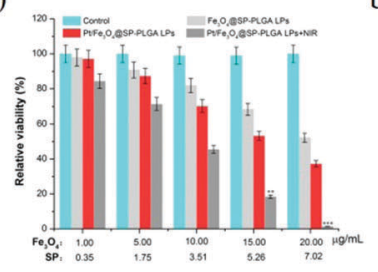

d)

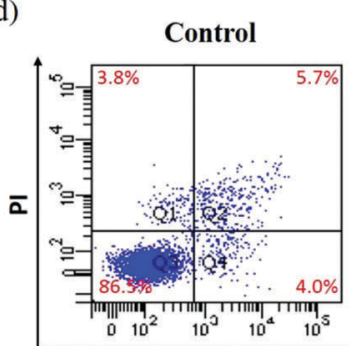

b)

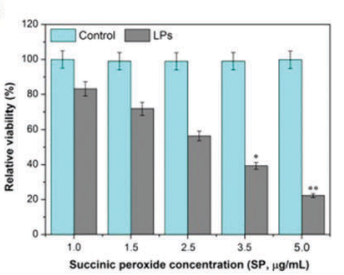

$\mathbf{P t} / \mathrm{Fe}_{3} \mathrm{O}_{4} @$ SP-PLGA

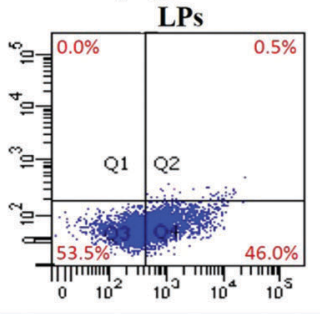

c)

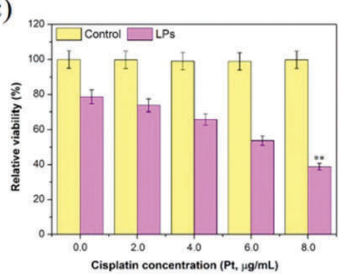

$\mathrm{Pt} / \mathrm{Fe}_{3} \mathrm{O}_{4} @ S P-P L G A$

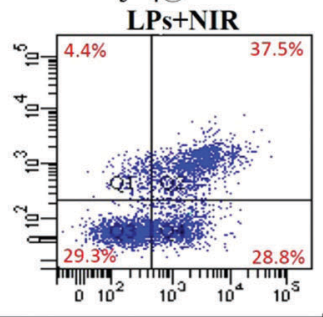

Fig. 5 (a) Quantitative evaluation of cell viability for MCF-7 cells treated with PBS, $\mathrm{Fe}_{3} \mathrm{O}_{4} @ \mathrm{CSP}-\mathrm{PLGA} L \mathrm{LS}, \mathrm{Pt} / \mathrm{Fe}_{3} \mathrm{O}_{4} @ \mathrm{CSP}-\mathrm{PLGA}$ LPs, and Pt/Fe $3 \mathrm{O}_{4} @$ SP-PLGA LPs + NIR for 24 h. (b) Quantitative evaluation of cell viability for MCF-7 cells treated with LPs at different SP concentrations. (c) Quantitative evaluation of cell viability for MCF-7 cells treated with LPs at different Pt concentrations. (d) The apoptosis of $\mathrm{MCF}^{-7}$ cells treated with Pt/Fe $\mathrm{O}_{4} \mathrm{a}^{\mathrm{a}}$ SP-PLGA LPS (NIR irradiation:,+-$)(n=3)$. *: $P<0.05 ; * *: P<0.01$.

were inevitably spread to various organs (liver, kidneys and other organs) of the body along with blood circulation at $12 \mathrm{~h}$ post-injection. However, the fluorescence signals in the tumor site remained remarkable. Moreover, the accumulation was still at a high level and mainly occurred in the tumor at $24 \mathrm{~h}$ post-injection. Thus, the images of mice treated with $\mathrm{Pt} / \mathrm{Fe}_{3} \mathrm{O}_{4} @ S P-P L G A$ LPs 


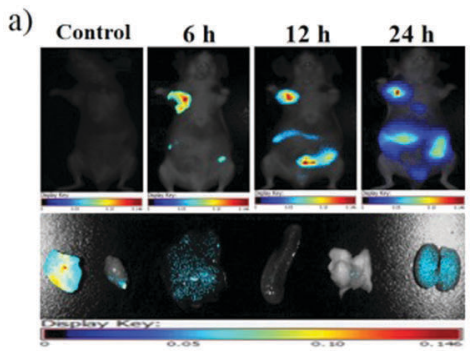

e)

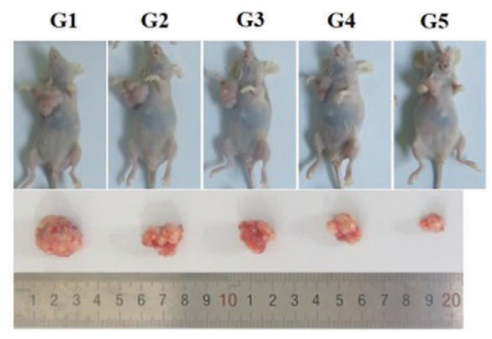

b)

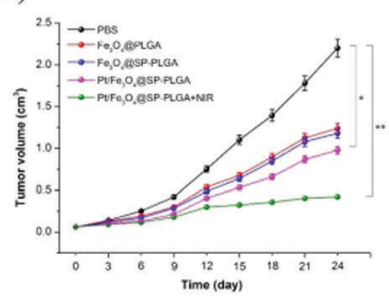

G1 c)

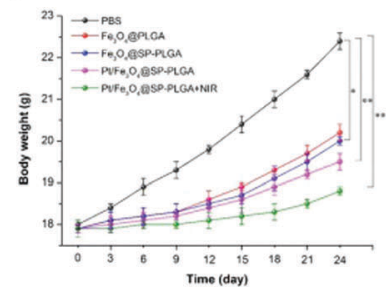

d)

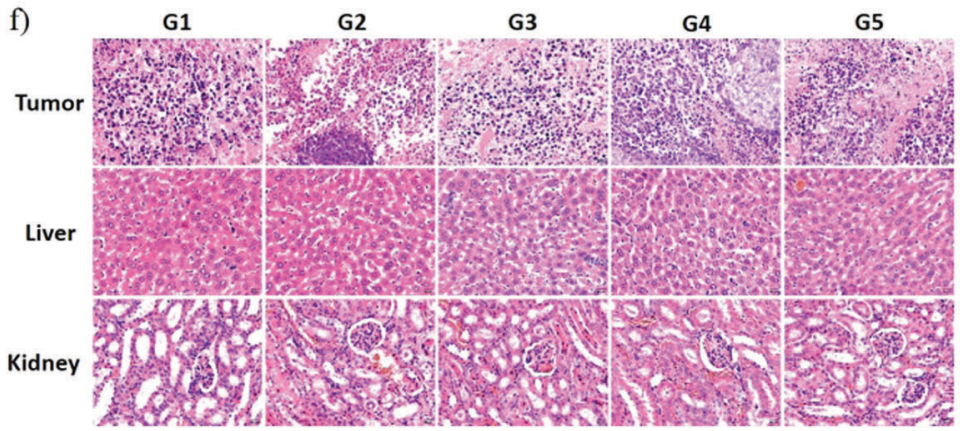

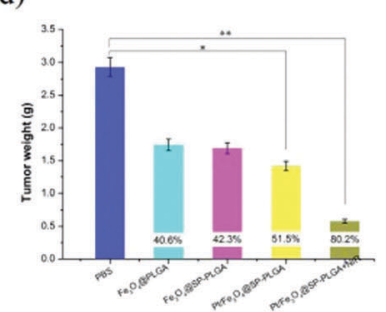

G5

Fig. 6 (a) In vivo fluorescence imaging of subcutaneous MCF-7 breast tumor-bearing nude mice after intratumoral injection of LPs and images of dissected organs of mice sacrificed $24 \mathrm{~h}$ after intratumoral injection of LPs. (b) Relative tumor volume growth curves in different groups of tumor-bearing mice after various treatments (normalized to their initial sizes). (c) Mouse weight growth curves in different groups of tumor-bearing mice after various treatments. Asterisk indicates $P<0.01$. Error bars represent the standard deviation of six mice per group. (d) The tumor weight in different groups of tumor-bearing mice after incubation for 24 days. Data are presented as the mean $\pm \operatorname{SD}\left(n=6,{ }^{*} p<0.05\right.$, ${ }^{*} p<0.01$ vs. PBS group). (e) Representative photographs of mice bearing MCF-7 breast tumors treated with PBS solution (G1), Fe $\mathrm{O}_{4}\left(\mathrm{QPLGA}(\mathrm{G} 2), \mathrm{Fe}_{3} \mathrm{O}_{4}\left(\mathrm{QSP}-\mathrm{PLGA}\right.\right.$ (G3), Pt/Fe $3 \mathrm{O}_{4}(\mathrm{QSP}-\mathrm{PLGA}$ (G4), and $\mathrm{Pt} / \mathrm{Fe}_{3} \mathrm{O}_{4} \mathrm{QSP}-\mathrm{PLGA}+\mathrm{NIR}$ (G5). (f) H\&E stained images of tumors and major organs from mice treated with different LP formations.

exhibited promising endocytosis and accumulation features in tumor tissues under the effect of the PEG-lecithin shells.

The images further showed that much stronger fluorescence signals were observed in the tumor site when compared with those accumulated in the liver, kidneys or other organs, which implies that the leaked LPs were less accumulated in other organs. The results of ICG imaging in vivo further demonstrated that the lipid-polymer hybrid structure could effectively reduce the clearance of small therapeutic molecules in the living body.

\subsection{In vivo antitumor therapy}

Next, we further applied the $\mathrm{Pt} / \mathrm{Fe}_{3} \mathrm{O}_{4} @$ @P-PLGA LPs to mice for antitumor therapy in vivo. As shown in Fig. 6b, compared with the tumor volume $\left(2.20 \mathrm{~mm}^{3}\right)$ in the PBS group, the tumors in group 2 and group 3 exhibited a moderate increase in the tumor volume to around 1.24 or $1.18 \mathrm{~cm}^{3}$, respectively, while the $\mathrm{Pt} / \mathrm{Fe}_{3} \mathrm{O}_{4} @ S P-P L G A$ group without NIR irradiation (group 4) showed a much lower tumor volume increase $\left(0.98 \mathrm{~cm}^{3}\right)$. However, the volume of the tumors treated with $\mathrm{Pt} / \mathrm{Fe}_{3} \mathrm{O}_{4} @$ @P-PLGA with NIR irradiation (group 5) was the lowest, and it increased slightly when compared with the normal volume that was induced by PBS (Fig. 6e).

As shown in Fig. 6c, compared with the body weight in group 5, the $\mathrm{Fe}_{3} \mathrm{O}_{4} @ P L G A, \mathrm{Fe}_{3} \mathrm{O}_{4} @ S P-P L G A$, and Pt/ $\mathrm{Fe}_{3} \mathrm{O}_{4} @$ @SP-PLGA groups showed an increase in body weight at different levels, indicating that the release of therapeutic agents was affected by NIR irradiation. The $\mathrm{Pt} / \mathrm{Fe}_{3} \mathrm{O}_{4} @$ @SP-PLGA without NIR irradiation group showed significant tumor suppression, while the
$\mathrm{Pt} / \mathrm{Fe}_{3} \mathrm{O}_{4} @ S P-P L G A$ with the NIR irradiation group caused ablation of the tumor to a considerable extent and exhibited $80.2 \%$ tumor inhibition after 24 days (Fig. $6 \mathrm{~d}$ ). During the 6 days of treatment, no significant body weight change was observed in all groups, showing that the prepared lipo-polymersomes had no significant side effects on the treated mice in antitumor therapy.

The tumors and normal organs were analyzed by H\&E staining to further investigate the ROS mediated cancer therapy effect and potential toxicity of the $\mathrm{Pt} / \mathrm{Fe}_{3} \mathrm{O}_{4} @ S P-P L G A$ LPs. As shown in Fig. 6f, compared with the PBS group (G1), the dose groups (G2, G3, and G4) clearly showed tumor necrosis and destroyed blood vessels, while the $\mathrm{Pt} / \mathrm{Fe}_{3} \mathrm{O}_{4} @$ @P-PLGA with NIR irradiation group (G5) induced the worst levels of tumor necrosis. The H\&E images of the major organs (liver and kidneys) from MCF-7 tumorbearing mice in all tested groups showed that there was no noticeable organ damage or inflammation lesion induced by the applied ROS mediated antitumor therapy. These results clearly demonstrate that $\mathrm{Pt} / \mathrm{Fe}_{3} \mathrm{O}_{4} @$ @P-PLGA LPs have high biocompatibility and can be applied as a nanotheranostic agent for imagingguided ROS mediated therapy of cancer.

\section{Conclusion}

In summary, we successfully developed a biocompatible and multifunctional $\mathrm{Pt} / \mathrm{Fe}_{3} \mathrm{O}_{4}$-engineered nanotheranostic agent for anticancer therapy. The $\mathrm{Pt} / \mathrm{Fe}_{3} \mathrm{O}_{4} @ S P-P L G A$ LPs showed low cytotoxicity, a high yield of ROS, and the ability to accumulate in tumor sites. The integration of FL intensity and ROS-mediated 
oxidative damage using $\mathrm{Pt} / \mathrm{Fe}_{3} \mathrm{O}_{4} @$ @P-PLGA LPs induced significant cell death in vitro and efficiently suppressed the MCF-7 tumor growth in vivo. These results demonstrate the potential therapeutic value of $\mathrm{Pt} / \mathrm{Fe}_{3} \mathrm{O}_{4} @$ @P-PLGA LPs for the ROS mediated therapy of solid tumors and create opportunities to significantly contribute toward the clinical translation of $\mathrm{Fe}_{3} \mathrm{O}_{4}$-based hybrid nanocomposites.

\section{Experimental section}

\subsection{Materials}

Lecithin and indocyanine green (ICG) were purchased from SigmaAldrich Chemical Company (St. Louis, MO, USA). Cisplatin (Pt) was purchased from Shandong Boyuan Pharmaceutical Co., Ltd (Jinan, Shandong, China). $\mathrm{Fe}_{3} \mathrm{O}_{4}$ NPs and $\mathrm{PEG}_{1 \mathrm{k}}-\mathrm{PLGA}_{1 \mathrm{k}}$ were synthesized and characterized according to previous studies. ${ }^{29-31}$ All the dye kits were obtained from Beyotime Biotechnology Co., Ltd (China). All the other chemical reagents were obtained from Sinopharm Chemical Reagent Co., Ltd.

\subsection{Instruments}

${ }^{1} \mathrm{H}-\mathrm{NMR}$ spectra were recorded on a Bruker AVANCE III HD-600 spectrometer using deuterated reagents as solvents. TEM images were obtained using a JEM-2100 transmission electron microscope at an acceleration voltage of $100 \mathrm{kV}$. The UV-Vis spectrometry was performed on a UV-2600. Hydrodynamic diameters were determined using a Malvern Zetasizer NanoZS system at $25{ }^{\circ} \mathrm{C}$. CLSM images were acquired using an LSM700 laser confocal microscope. Flow cytometry experiments were conducted using a BD LSRFortessa X-20 cell analyzer.

\subsection{Synthesis of succinic peroxide (SP)}

$\mathrm{H}_{2} \mathrm{O}_{2}$ aqueous solution (6.00 g, 30\%) was added to succinic acid $(4.00 \mathrm{~g}, 0.03 \mathrm{~mol})$ in a round bottom flask $(50 \mathrm{~mL})$ and the mixture was stirred at $10{ }^{\circ} \mathrm{C}$ for $2 \mathrm{~h}$. The solution was cooled in the refrigerator and a white solid was then precipitated, which was filtered, washed with water and then dried. Yield: $86 \%$ (6.82 $\mathrm{g}, 0.03 \mathrm{mmol}) .{ }^{1} \mathrm{H}$ NMR (600 MHz, DMSO-d $\left.{ }_{6}\right): \delta(\mathrm{ppm}) 4.00$ (b, 8H). ESI-MS $(m / z): 235.23[\mathrm{M}+\mathrm{H}]^{+}$.

\subsection{Synthesis of the grafted SP polymers}

The coupled polymer ((PEG-PLGA) $)_{2}$-SP, PLGA-SP) was obtained from conjugated succinic peroxide (SP) and $\mathrm{PEG}_{1 \mathrm{k}}-\mathrm{PLGA}_{1 \mathrm{k}}-\mathrm{OH}$ (or PLGA $\left._{1 \mathrm{k}}-\mathrm{OH}\right)$. Briefly, SP $(0.07 \mathrm{~g}, 0.3 \mathrm{mmol})$, EDCl (0.12 g, $0.6 \mathrm{mmol})$, and NHS $(0.07 \mathrm{~g}, 0.6 \mathrm{mmol})$ were dissolved in DMF $(35 \mathrm{~mL})$ in an ice-water bath and kept stirring for $2 \mathrm{~h}$, then $\mathrm{PEG}_{1 \mathrm{k}}-\mathrm{PLGA}_{1 \mathrm{k}}-\mathrm{OH}(2.40 \mathrm{~g}, 0.6 \mathrm{mmol})$ was added and reacted overnight at room temperature. Then, the mixture solution was washed with water and extracted with DCM. The desired intermediate products were obtained after having been concentrated and freeze-dried for further use. (PEG-PLGA) $)_{2}$-SP was recovered as a colorless viscous solid (1.85 g, 76\%). ${ }^{1} \mathrm{H}$ NMR $\left(600 \mathrm{MHz}, \mathrm{CDCl}_{3}\right): \delta(\mathrm{ppm}) 5.18(\mathrm{~b}, 1 \mathrm{H}), 4.99(\mathrm{~b}, 4 \mathrm{H})$ 4.84-4.65 (d, 1H), 3.68-3.53 (b, 10H), 2.40 (b, 3H), 2.18 (b, 1H), 1.60-1.47 $(\mathrm{d}, 3 \mathrm{H})$. GPC $\left(M_{\mathrm{w}}\right)$ : 4412 Da. PLGA-SP was recovered as a colorless viscous solid $(0.25 \mathrm{~g}, 68 \%) .{ }^{1} \mathrm{H}$ NMR $(600 \mathrm{MHz}$, $\left.\mathrm{CDCl}_{3}\right): \delta(\mathrm{ppm}) 5.18(\mathrm{~b}, 1 \mathrm{H}), 4.91(\mathrm{~b}, 2 \mathrm{H}), 3.63(\mathrm{~b}, 3 \mathrm{H}), 2.36$ (b, 2H), $2.18(\mathrm{~b}, 2 \mathrm{H}), 1.60-1.50(\mathrm{~d}, 3 \mathrm{H})$. GPC $\left(M_{\mathrm{w}}\right)$ : $1310 \mathrm{Da}$.

\subsection{Formation of $\mathrm{Fe}_{3} \mathrm{O}_{4}$ and Pt loaded polymersomes

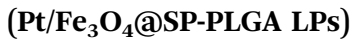

We prepared the present nanocarriers with w/o/w layered structures by double emulsification. In the first emulsion process, the oil-phase solution (DCM $5 \mathrm{~mL}$, containing (PEG-PLGA) ${ }_{2}$-SP $3.0 \mathrm{mg}$, PLGA-SP $5.0 \mathrm{mg}$, and lecithin $22.0 \mathrm{mg}$ ) was slowly added into a PVA aqueous solution (contain $0.125 \mathrm{mg} \mathrm{mL}^{-1}$ ICG and $0.167 \mathrm{mg} \mathrm{mL} \mathrm{mL}^{-1} \mathrm{Pt}$ ) under sonication accompanied by icewater bath conditions for $2 \mathrm{~h}$. This process can generate w/o PLGA-lipid polymersomes. In the next step, 2000 ppm $\mathrm{Fe}_{3} \mathrm{O}_{4}$ NPs were dispersed in $0.5 \mathrm{~mL}$ of DCM and then added to the first emulsion solution. To embed the $\mathrm{Fe}_{3} \mathrm{O}_{4}$ NPs into the PLGA-lipid shell, the $\mathrm{Fe}_{3} \mathrm{O}_{4}$ NPs were dropwised in $12 \mathrm{~mL}$ of (10 $\mathrm{mg} \mathrm{mL}^{-1}$ ) PVA aqueous solution, then the second emulsion was performed using an ultrasonic homogenizer apparatus in an ice bath for $20 \mathrm{~min}$ to form w/o/w Pt/ $\mathrm{Fe}_{3} \mathrm{O}_{4} @ S P-P L G A$ lipopolymersomes.

\subsection{Drug release}

The drug release investigation of the $\mathrm{Pt} / \mathrm{Fe}_{3} \mathrm{O}_{4} @$ @SP-PLGA LPs was undertaken using a dialysis method, as our previous work described. ${ }^{32-34}$ A predetermined amount of the prepared polymersomes $\left(3 \mathrm{~mL}, 1.5 \mathrm{mg} \mathrm{mL}^{-1}\right)$ in dialysis tubing $\left(M_{\mathrm{w}}, 15000\right)$ was immersed in phosphate buffered saline (PBS, $\mathrm{PH}=7.4$ and 5.5) as dissolution media. The release investigation was done with near-infrared laser (808 $\mathrm{nm}, 1.5 \mathrm{~W}, 5 \mathrm{~min})$ irradiation $(+,-)$. At the designed time intervals, a certain volume $(2 \mathrm{~mL})$ of the release medium was taken out and the amount of Pt or $\mathrm{Fe}_{3} \mathrm{O}_{4}$ present in the dialysate was calculated by ICP-AES. The releasing experiments were tested in triplicate, and the mean value was calculated as the final result.

\subsection{Cellular uptake study}

Human breast cancer cells (MCF-7) were cultured with DMEM medium (containing 10\% FBS and 1\% penicillin-streptomycin) under a $5 \% \mathrm{CO}_{2}$ atmosphere at $37{ }^{\circ} \mathrm{C}$. In the CLSM study, MCF-7 cells were severally seeded in a confocal culture dish $(2 \mathrm{~mL}$ medium) at a density of $7.0 \times 10^{4}$ cells per dish. After being cultured under a $5 \% \mathrm{CO}_{2}$ atmosphere at $37{ }^{\circ} \mathrm{C}$ for $24 \mathrm{~h}$, a predesigned amount of $\mathrm{Pt} / \mathrm{Fe}_{3} \mathrm{O}_{4} @ S P-P L G A$ LP suspension $\left(2 \mathrm{~mL}\right.$ ) with an equivalent ICG concentration of $45 \mu \mathrm{g} \mathrm{mL}{ }^{-1}$ was added into the cell culture medium. After further incubation for 1,3 , and $12 \mathrm{~h}$, respectively, the culture medium was removed, and the cells were washed three times with PBS. Then, the cells were stained with DAPI and further mounted for observation with CLSM. Finally, the fluorescence intensity of the cellular uptake was calculated using a flow cytometer.

\subsection{ROS generated in mitochondria}

The experimental process of mitochondrial observation was performed as described above but the cells were stained with Lysotracker Green (lysosome staining, green color). The induced singlet 
oxygen was generated by the $\mathrm{Pt} / \mathrm{Fe}_{3} \mathrm{O}_{4} @$ @PP-PLGA LPs and the intracellular ROS was detected by an oxidation-sensitive fluorescent probe (DCFH-DA). ${ }^{35}$ Briefly, MCF-7 cells were seeded in 6-well plates and further incubated for $0.5 \mathrm{~h}, 1.0 \mathrm{~h}, 3.0 \mathrm{~h}$, and $6.0 \mathrm{~h}$ after having been treated with $\mathrm{Pt} / \mathrm{Fe}_{3} \mathrm{O}_{4} @$ @SP-PLGA LPs $\left(25 \mu \mathrm{g} \mathrm{mL}{ }^{-1}\right)$. In addition, the cells were incubated for $6 \mathrm{~h}$ after having been treated with $\mathrm{Pt} / \mathrm{Fe}_{3} \mathrm{O}_{4} @$ @SP-PLGA LPs at concentrations of 10, 20 and $30 \mu \mathrm{g} \mathrm{mL}{ }^{-1}$. Similarly, the cells were incubated for $6 \mathrm{~h}$ after having been treated with PBS, $\mathrm{Fe}_{3} \mathrm{O}_{4} @ P L G A, \mathrm{Fe}_{3} \mathrm{O}_{4} @ S P-P L G A$, $\mathrm{Pt} / \mathrm{Fe}_{3} \mathrm{O}_{4} @ S P-P L G A$ LPs and $\mathrm{Pt} / \mathrm{Fe}_{3} \mathrm{O}_{4} @$ @SP-PLGA LPs upon NIR irradiation (1.5 W, 5 min per dish) at a concentration of $30 \mu \mathrm{g} \mathrm{mL}^{-1}$. Then, DCFH-DA $(10 \mu \mathrm{M})$ was employed to measure the ROS released by the Fenton-like reaction. Finally, the fluorescence intensity of ROS production in the MCF-7 cells was quantitated using a flow cytometer.

\subsection{In vitro cytotoxicity study}

To evaluate the cytotoxicity of the $\mathrm{Pt} / \mathrm{Fe}_{3} \mathrm{O}_{4} @$ @P-PLGA LPs, MCF-7 cells were seeded into $96-w e l l$ plates (100 $\mu \mathrm{L}$ medium) and incubated overnight. When the cell confluence reached around $70 \%$, the medium was replaced with fresh DMEM containing different formulations of LP suspensions with various $\mathrm{Fe}_{3} \mathrm{O}_{4}$ concentrations $\left(1.0,5.0,10.0,15.0\right.$, and $\left.20.0 \mu \mathrm{g} \mathrm{mL}{ }^{-1}\right)$. After $12 \mathrm{~h}$ of incubation, the medium was replaced, and the cells were further irradiated with an $808 \mathrm{~nm}$ NIR laser $\left(1.5 \mathrm{~W}, 3 \mathrm{~s}\right.$ well $\left.{ }^{-1}\right) .^{36}$ After incubation for another $12 \mathrm{~h}$, the standard MTT assay was performed to evaluate the cell viability. In addition, we further evaluated the cytotoxicity of the $\mathrm{Pt} / \mathrm{Fe}_{3} \mathrm{O}_{4} @$ @P-PLGA LPs on MCF-7 cells, which were encapsulated with different concentrations of SP $\left(1.0,1.5,2.5,3.5\right.$, and $\left.5.0 \mu \mathrm{g} \mathrm{mL}^{-1}\right)$ or cisplatin $(0.0,2.0,4.0,6.0$, and $8.0 \mu \mathrm{g} \mathrm{mL}^{-1}$ ) in the same way.

\subsection{Cell apoptosis}

To further evaluate the effect of the prepared lipo-polymersomes on cell apoptosis under irradiation, MCF-7 cells were incubated in

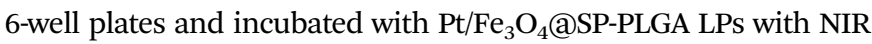
irradiation $(+,-)$. The untreated group was used as the control. The cell samples were incubated for a further $12 \mathrm{~h}$ after having been dosed for $12 \mathrm{~h}$ and irradiated for $5 \mathrm{~min}$. The results were analyzed by flow cytometry (FCM) after staining with Annexin V and PI.

\subsection{Animal experiments and tumor models}

Female BABL/c nude mice (each 18-22 g) were purchased from Shanghai Lingchang Biotechnology Co. Ltd (Shanghai, China) and raised under the principles of care and use of laboratory animals. The MCF-7 tumor models were generated by the subcutaneous injection of $100 \mu \mathrm{L}$ of cell suspension (in saline medium, $1 \times 10^{7}$ cells $\mathrm{mL}^{-1}$ ) into the right flank of each mouse. After incubation for 12 days, the mice were used for further experiments when the tumor size had grown to $\sim 60 \mathrm{~mm}^{3}$.

\subsection{In vivo imaging and biodistribution analysis}

The nude mice were intratumorally injected with $200 \mu \mathrm{L}$ of $\mathrm{Pt} / \mathrm{Fe}_{3} \mathrm{O}_{4} @$ @P-PLGA LP solutions, containing $55 \mu \mathrm{g} \mathrm{mL}{ }^{-1}$ ICG. Images and FL quantitative analysis of ICG were taken at 0,6 ,
12 , and $24 \mathrm{~h}$ after injection using the ex/in vivo imaging system (CRI maestro, USA) with a $704 \mathrm{~nm}$ excitation wavelength and a $735 \mathrm{~nm}$ filter to collect the FL signals of ICG. The mice were sacrificed after injection for $24 \mathrm{~h}$ and the organs including the heart, liver, spleen, lung, kidneys and tumor were collected for imaging and quantitative biodistribution analysis.

\subsection{In vivo antitumor efficacy studies using a breast cancer model}

MCF-7 tumor-bearing mice (6/group) were randomly divided into five groups and intratumorally injected with $200 \mu \mathrm{L}$ of Fe-Pt@INP polymersome solution (containing $29.43 \mu \mathrm{g}$ of $\mathrm{Fe}_{3} \mathrm{O}_{4}, 10.32 \mu \mathrm{g}$ SP and $14.55 \mu \mathrm{g}$ of $\mathrm{Pt}$ ) and group 5 was further irradiated with an $808 \mathrm{~nm}$ NIR laser (1.5 W, $5 \mathrm{~min}$ ). The mice were injected five times in total (once every 3 days). The tumor sizes were measured using an electronic digital caliper every three days after treatment and calculated as follows: tumor volume $(\mathrm{TV})=0.5 \times($ tumor length $) \times(\text { tumor width })^{2}$. The relative tumor volumes (RTVs) were normalized to their initial sizes. To further detect the effect of enhanced chemo-photothermal therapy in vivo, the tumors, livers and kidneys at $24 \mathrm{~d}$ after treatment were stained with hematoxylin and eosin.

\section{Statement}

All animal experiments in this research work complied with the Regulations on the Administration of Laboratory Animals and the relevant national laws and regulations, and were performed under the guidance approved by the Laboratory Animal Ethics Committee at School of Medicine, Southeast University (Nanjing, China).

\section{Conflicts of interest}

There are no conflicts to declare.

\section{Acknowledgements}

We are highly grateful for the financial support from the National Natural Science Foundation of China (Grant No. 21628101), the International S\&T Cooperation Program of China (No. 2015DFG42240), the National Key Research and Development Program of China (2016YFD0600801), the Top-notch Academic Programs Project of Jiangsu Higher Education Institutions (TAPP, Grant No. PPZY2015C221) and the Priority Academic Program Development of Jiangsu Higher Education Institutions (PAPD).

\section{References}

1 D. Dolmans, D. Fukumura and R. K. Jain, Nat. Rev. Cancer, 2003, 3, 380-387.

2 P. Agostinis, K. Berg, K. A. Cengel, T. H. Foster, A. W. Girotti and J. Golab, Ca-Cancer J. Clin., 2011, 61, 250-281. 
3 S. H. Voon, L. V. Kiew, H. B. Lee, S. H. Lim, M. I. Noordin, A. Kamkaew, K. Burgess and L. Y. Chung, Small, 2015, 10, 4993-5013.

4 S. B. Brown, E. A. Brown and I. Walker, Lancet Oncol., 2004, 5, 497-508.

5 W. Fan, P. Huang and X. Chen, Chem. Soc. Rev., 2016, 45, 6488-6519.

6 H. Chen, G. D. Wang, Y.-J. Chuang, Z. Zhen, X. Chen, P. Biddinger, Z. Hao, F. Liu, B. Shen, Z. Pan and J. Xie, Nano Lett., 2015, 15, 2249-2256.

7 Y. L. Dai, Z. Yang, S. Y. Cheng, Z. L. Wang, R. L. Zhang, G. Z. Zhu, Z. T. Wang, B. C. Yung, R. Tian, O. Jacobson, C. Xu, Q. Q. Ni, J. B. Song, X. L. Sun, G. Niu and X. Y. Chen, Adv. Mater., 2018, 30, 1704877.

8 G. Song, C. Liang, X. Yi, Q. Zhao, L. Cheng, K. Yang and Z. Liu, Adv. Mater., 2016, 28, 2716-2723.

9 P. D. Ray, B.-W. Huang and Y. Tsuji, Cell. Signalling, 2012, 24, 981-990.

10 P. T. Schumacker, Cancer Cell, 2015, 27, 156-157.

11 S. J. Dixon, K. M. Lemberg, M. R. Lamprecht, R. Skouta, E. M. Zaitsev, C. E. Gleason, D. N. Patel, A. J. Bauer, A. M. Cantley, W. S. Yang, B. Morrison and B. R. Stockwell, Cell, 2012, 149, 1060-1072.

12 Z. Zhou, J. Song, R. Tian, Z. Yang, G. Yu, L. Lin, G. Zhang, W. Fan, F. Zhang, G. Niu, L. Nie and X. Chen, Angew. Chem., Int. Ed., 2017, 56, 6492-6496.

13 Y. Liu, P. C. Naha, G. Hwang, D. Kim, Y. Huang, A. Simon-Soro, H. Jung, Z. Ren, Y. Li, S. Gubara, F. Alawi, D. Zero, A. T. Hara, D. P. Cormode and H. Koo, Nat. Commun., 2018, 9, 2920.

14 L. Gao, Y. Liu, D. Kim, Y. Li, G. Hwang, P. C. Naha, D. P. Cormode and H. Koo, Biomaterials, 2016, 101, 272-284.

15 N. Teraphongphom, P. Chhour, J. R. Eisenbrey, P. C. Naha, W. R. T. Witschey, B. Opasanont, L. Jablonowski, D. P. Cormode and M. A. Wheatley, Langmuir, 2015, 31, 11858-11867.

16 P. Chhour, N. Gallo, R. Cheheltani, D. Williams, A. Al-Zaki, T. Paik, J. L. Nichol, Z. Tian, P. C. Naha, W. R. Witschey, H. R. Allcock, C. B. Murray, A. Tsourkas and D. P. Cormode, ACS Nano, 2014, 8, 9143-9153.

17 S. J. Sun, Y. X. Xu, P. Fu, M. Chen, S. H. Sun, R. R. Zhao, J. R. Wang, X. L. Liang and S. M. Wang, Nanoscale, 2018, 10, 19945-19956.

18 Z. Tang, H. Zhang, Y. Liu, D. Ni, H. Zhang, J. Zhang, Z. Yao, M. He, J. Shi and W. Bu, Adv. Mater., 2017, 29, 1701683.
19 Z. M. Liu, H. L. Chen, Y. L. Jia, W. Zhang, H. N. Zhao, W. D. Fan, W. L. Zhang, H. Q. Zhong, Y. R. Nia and Z. Y. Guo, Nanoscale, 2018, 10, 18795-18804.

20 T. Itoh, R. Terazawa, K. Kojima, K. Nakane, T. Deguchi, M. Ando, Y. Tsukamasa, M. Ito and Y. Nozawa, Free Radical Res., 2011, 45, 1033-1039.

21 H.-J. Kim, J.-H. Lee, S.-J. Kim, G. S. Oh, H.-D. Moon, K.-B. Kwon, C. Park, B. H. Park, H.-K. Lee and S.-Y. Chung, J. Neurosci., 2010, 30, 3933-3946.

22 C. Q. You, H. S. Wu, Z. G. Gao, K. Sun, F. H. Chen, W. A. Tao and B. W. Sun, J. Mater. Chem. B, 2018, 6, 6752-6766.

23 Z. M. Tang, Y. Y. Liu, M. Y. He and W. B. Bu, Angew. Chem., Int. Ed., 2018, 57, 2-13.

24 R. A. Gatenby and R. J. Gillies, Nat. Rev. Cancer, 2004, 4, 891-899.

25 A. Sorkin and M. V. Zastrow, Nat. Rev. Mol. Cell Biol., 2002, 3, 600-614.

26 C. Q. You, J. Yu, Y. Sun, Y. H. Luo, X. Y. Zhang, J. Zhu and B. W. Sun, New J. Chem., 2017, 41, 773-785.

27 R. Li, N. D. Mansukhani, L. M. Guiney, Z. Ji, Y. Zhao, C. H. Chang, C. T. French, J. F. Miller, M. C. Hersam, A. E. Nel and T. Xia, ACS Nano, 2016, 10, 10966-10980.

28 S. Clement, W. Deng, E. Camilleri, B. C. Wilson and E. M. Goldys, Sci. Rep., 2016, 6, 19954.

29 Z. G. Gao, Y. J. Li, C. Q. You, K. Sun, P. J. An, C. Sun, M. X. Wang, X. L. Zhu and B. W. Sun, ACS Appl. Bio Mater., 2018, 1, 270-280.

30 C. Q. You, H. S. Wu, M. X. Wang, Y. W. Zhang, J. W. Wang, Y. H. Luo, L. H. Zhai, B. W. Sun, X. Y. Zhang and J. Zhu, Chem. - Eur. J., 2017, 23, 5352-5360.

31 K. Sun, Z. G. Gao, Y. Zhang, H. S. Wu, C. Q. You, S. L. Wang, P. J. An, C. Sun and B. W. Sun, J. Mater. Chem. B, 2018, 6, 5876-5887.

32 C. Q. You, Z. G. Gao, M. X. Wang, H. S. Wu, P. J. An, S. L. Wang, Y. Sun, B. W. Sun and X. Y. Zhang, Mater. Sci. Eng., C, 2019, 95, 183-191.

33 C. Q. You, H. S. Wu, M. X. Wang, Z. G. Gao, B. W. Sun and X. Y. Zhang, Mater. Sci. Eng., C, 2018, 92, 453-463.

34 C. Q. You, H. S. Wu, M. X. Wang, Z. G. Gao, X. Y. Zhang and B. W. Sun, Nanotechnology, 2018, 29, 015601.

35 C. Q. You, M. X. Wang, H. S. Wu, P. J. An, M. M. Pan, Y. H. Luo and B. W. Sun, Mater. Sci. Eng., C, 2017, 80, 362-370.

36 C. Q. You, H. S. Wu, M. X. Wang, S. L. Wang, T. Y. Shi, Y. H. Luo, B. W. Sun, X. Y. Zhang and J. Zhu, Nanotechnology, 2017, 28, 165102. 